
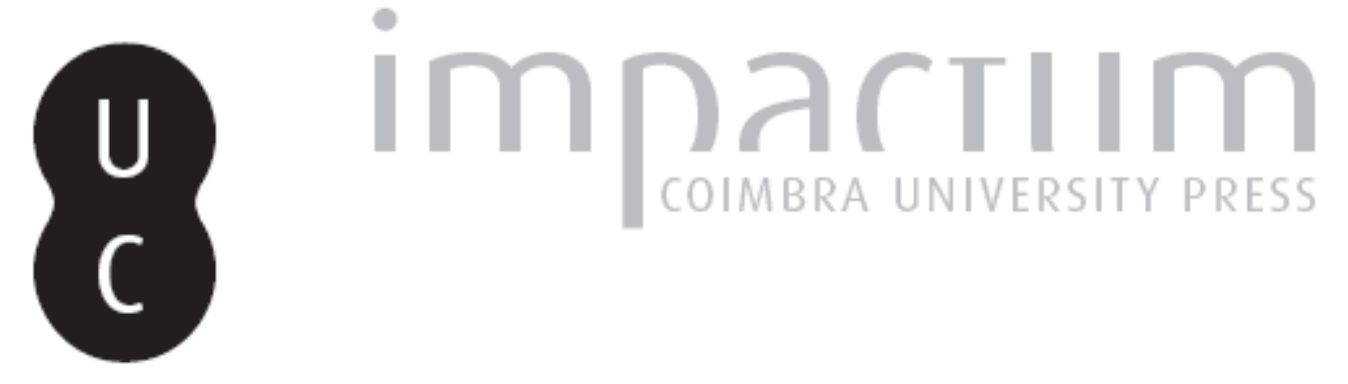

\title{
O sítio arqueológico da "Casinha Derribada": enquadramento geológico e geomorfologia
}

\author{
Autor(es): $\quad$ Simões, Luís M. F.
}

Publicado por: Imprensa da Universidade de Coimbra

URL persistente:

URI:http://hdl.handle.net/10316.2/45404

DOI:

DOI:https://dx.doi.org/10.14195/1647-8657_37_2

Accessed : $\quad$ 26-Apr-2023 16:09:35

A navegação consulta e descarregamento dos títulos inseridos nas Bibliotecas Digitais UC Digitalis, UC Pombalina e UC Impactum, pressupõem a aceitação plena e sem reservas dos Termos e Condições de Uso destas Bibliotecas Digitais, disponíveis em https://digitalis.uc.pt/pt-pt/termos.

Conforme exposto nos referidos Termos e Condições de Uso, o descarregamento de títulos de acesso restrito requer uma licença válida de autorização devendo o utilizador aceder ao(s) documento(s) a partir de um endereço de IP da instituição detentora da supramencionada licença.

Ao utilizador é apenas permitido o descarregamento para uso pessoal, pelo que o emprego do(s) título(s) descarregado(s) para outro fim, designadamente comercial, carece de autorização do respetivo autor ou editor da obra.

Na medida em que todas as obras da UC Digitalis se encontram protegidas pelo Código do Direito de Autor e Direitos Conexos e demais legislação aplicável, toda a cópia, parcial ou total, deste documento, nos casos em que é legalmente admitida, deverá conter ou fazer-se acompanhar por este aviso.

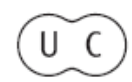


UNIVERSIDADE DE COIMBRA

FACULDADE DE LETRAS

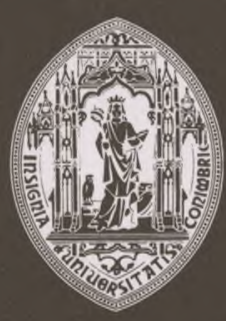

\section{CONIMBRIGA}

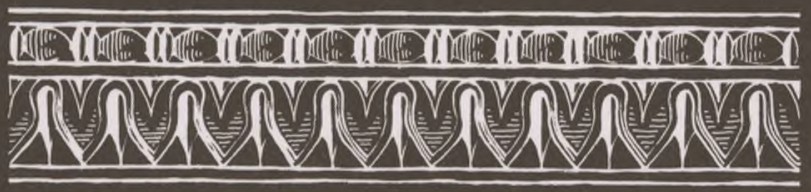

VOLUME XXXVII - 1998 
Luís M. F. SIMõES

Instituto Superior Politécnico de Viseu

O SÍTIO ARQUEOLÓGICO DA "CASINHA DERRIBADA". ENQUADRAMENTO GEOLÓGICO E GEOMORFOLOGIA

Conimbriga", XXXVII (1998), p. 77-81

Resumo: No contexto dos trabalhos arqueológicos da "Casinha Derribada", faz-se a caracterização geológica e geomorfológica da área onde se implantam os pequenos tumuli da "Casinha Derribada".

ABSTRACT: Within the context of the archaeological works done at "Casinha Derribada", we present herewith the geological and geomorphological framing of the area where the small tumuli of "Casinha Derribada".

Conimbriga, 37 (1998), 77-81 
(Página deixada propositadamente em branco) 


\section{O SÍTIO ARQUEOLÓGICO DA "CASINHA DERRIBADA" ENQUADRAMENTO GEOLÓGICO E GEOMORFOLOGIA}

A região onde se encontram implantados os monumentos da "Casinha Derribada" é abrangida pela folha 178 (Viseu) da carta topográfica editada pelos Serviços Cartográficos do Exército, à escala de 1: 25.000, e insere-se na Zona Centro-Ibérica, na parte interna do orógeno hercínico.

Num polígono inscrito a norte da cidade de Viseu e delimitado a oeste pela povoação do Campo e a este por Cavernães, afloram metassedimentos do "Complexo Xisto-grauváquico das Beiras" (C.X.G.), de idade ante-ordovícica, e diversos corpos granitóides hercínicos com características estruturais, texturais e mineralógicas muito variadas (Fig. 1).

Os monumentos em apreço estão implantados no bordo sul de uma superfície de aplanamento com segmentos bem conservados a altitudes variáveis entre os 600 e os 680 metros, designada por "superfície superior de Viseu"; esta confronta a norte de Viseu com uma segunda superfície de aplanamento com cotas menos elevadas, em tomo dos 500 metros, e na qual assenta aquela cidade. Tal superfície corresponde ao sector setentrional da plataforma do rio Mondego (Ferreira, 1978). Segundo este autor o contacto entre estas duas superfícies de aplanamento é bastante sinuoso. No sector em causa, o contacto sul é nítido e sublinhado por um rebordo de cerca de 100 metros de altura, com um declive que atinge $10 \%$ a este da povoação do Campo e $22 \%$ na zona de Santa Luzia. Pelo contrário, o troço oeste do rebordo só localmente tem expressão clara, havendo quase sempre uma passagem gradual da superfície inferior para a superfície superior. Do ponto de vista geomorfológico, os monumentos localizam-se na plataforma que separa a bacia hidrográfica do rio Vouga, a norte, da bacia hidrográfica do rio Mondego, a sul e a sudeste.

Conimbriga, 37 (1998), 77-81 
$\mathrm{Na}$ superfície de aplanamento correspondente ao sector setentrional da plataforma do rio Mondego e a sul da área em apreço, afloram sobretudo granitóides predominantemente biotíticos, porfiróides de grão médio a grosseiro tardi e pós-tectónicos. $\mathrm{Na}$ superfície superior de Viseu ocorrem granitóides de duas micas, equigranulares de grão médio a fino, tardia a sintectónicos, xistos, micaxistos e grauvaques com grau de metamorfismo diverso desde a zona da biotite à zona da silimanite.

Do ponto de vista geológico, o segmento de crusta onde os monumentos em estudo estão localizados é constituído por uma mancha de micaxistos pertencente ao "Complexo Xisto-grauváquico das Beiras", de idade ante-ordovícica. Tais micaxistos exibem grandes porfiroblastos prismáticos de estaurolite que se encontram profundamente substituídos por sericite e por moscovite; outros constituintes mineralógicos ubíquos são a clorite, a biotite e o quartzo; a turmalina é frequente e a andaluzite substitui por vezes a estaurolite.

Em termos gerais estas duas superfícies de aplanamento correspondem a substratos geológicos diferenciados e são o produto de processos de erosão diferencial e das diferentes etapas orogénicas e consequente evolução geológica e geomorfológica do Norte e Centro de Portugal Continental.

O relevo de toda a região é condicionado pela existência de linhas de água com orientação preferencial NNE-SSW, NE-SW, ENE-WSW e NNW-SSE, adaptadas geralmente à fracturação regional e originando, em áreas graníticas, vales encaixados; em zonas metassedimentares, os vales são abertos e pouco profundos. Entre as linhas de água o relevo mostra-se algo aplanado com perfil geomorfológico arredondado. Em toda a região o padrão geral da rede de drenagem é do tipo dendritico, apesar da frequência com que ocorrem troços de configuração rectilínea, que reflectem o condicionamento estrutural da implantação de tal padrão.

A região é fundamentalmente agrícola. As explorações fazem-se preferencialmente nos retalhos xistosos, mais fáceis de trabalhar. Nos vales mais largos o aproveitamento dos depósitos aluvionares e coluvionares é frequente mas, na maioria dos casos, de importância limitada. 


\section{BIBLIOGRAFIA}

FERREIRA, A. B. (1978) — Planaltos e montanhas do Norte da Beira. Estudo de geomorfologia. Lisboa. ["Memórias do Centro de Estudos Geográficos”, 4]. SOEN, O. I (1958) - "The geology, petrology and ore deposits of the Viseu region, Northern Portugal". Com. Serv. Geol. Portugal, 41. Lisboa.

SCHERMERHORN, L. J. G. (1956) - "Igneous, metamorphic and geology of the Castro Daire - São Pedro do Sul - Sátão region (northern Portugal)”. Com. Serv. Geol. Portugal, 37. Lisboa.
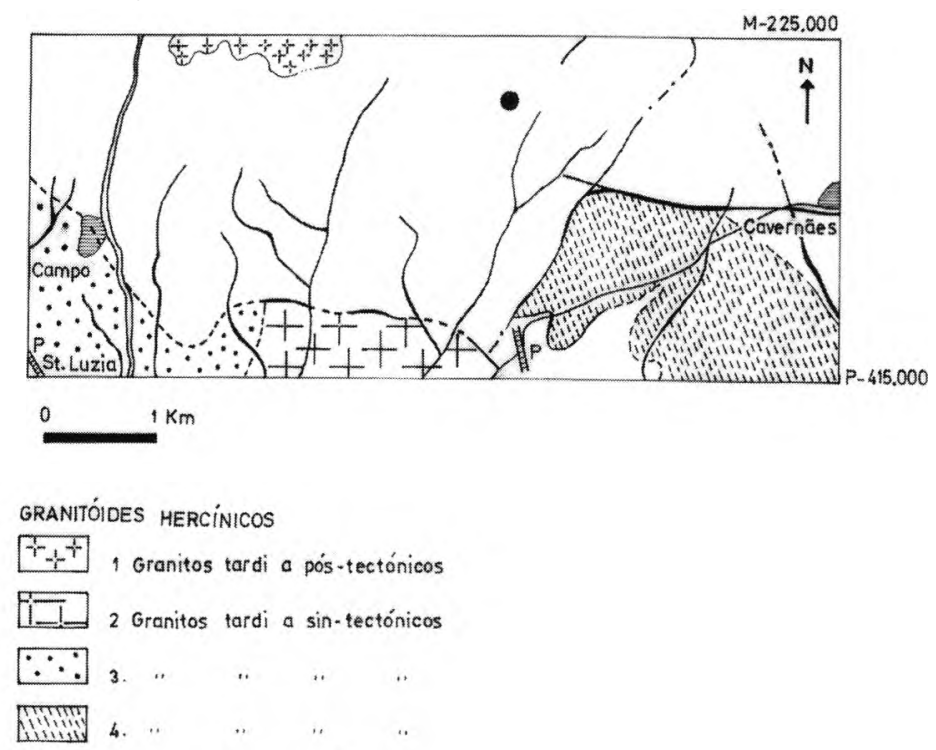

METASEDIMENTOS ANTE-ORDOVÍCICOS

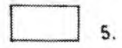

P PEGMATITO

-. - Falha observada; falha interida

- - - Contacto geológico observado: Cont. geo. provável

Localizacäo dos monumentos

Fig. 1 - Esboço geológico, modificado e simplificado, de Soen (1958) e de Schermerrhorn (1956). Granitóides hercínicos: (1) granito de duas micas, equigranular de grão médio; (2) granito de duas micas, equigranular de grão médio a grosseiro com foliação observável; (3) granito de duas micas, equigranular de grão médio a fino com foliação observável; (4) granito biotítico com moscovite, equigranular de grão médio com foliação observável; (5) xistos, micaxistos, grauvaques e migmatitos do "complexo xisto-grauváquico das Beiras". 